\title{
Clinical Study of a Newly Diagnosed Case of Gitelman Syndrome in a Patient Monitored for Liddle Syndrome
}

\author{
Jun Hyung Park, Hyung Young Kim, Da Hee Kim, Ji Won Kim, Sang Hyun Kim, Won Do Park \\ Department of Internal Medicine, Inje University Sanggye Paik Hospital, Inje University College of Medicine, Seoul, Korea
}

\begin{abstract}
A 55-year-old man who had been monitored for Liddle syndrome in the nephrology division for 15 years visited again Inje University Sanggye Paik Hospital for a newly developed electrolyte disorder. Because his blood pressure was normal and he showed hypomagnesemia and hypokalemia, a renal clearance test and renal biopsy were conducted for suspected Gitelman syndrome. The patient was diagnosed with Gitelman syndrome, which has been previously reported 12 cases in South Korea. The renal clearance test revealed a disorder of the $\mathrm{Na}-\mathrm{Cl}$ cotransporter (NCCT) in the distal tubule, while the renal biopsy revealed partial expression of NCCT, typical of Gitelman syndrome. Currently, the patient is being monitored, and is receiving oral administration of calcium and magnesium.
\end{abstract}

Keywords: Gitelman syndrome; Liddle syndrome; Hypomagnesemia; Hypokalemia; Solute carrier family 12, member 3

\section{INTRODUCTION}

Gitelman syndrome is an autosomal recessive genetic renal tubule disease characterized by hypokalemia, metabolic alkalosis, hypocalcemia, and hypomagnesemia [1,2]. This syndrome occurs because of a disorder of the $\mathrm{Na}-\mathrm{Cl}$ cotransporter (NCCT) in the distal tubule caused by mutation of (the solute carrier family 12 [sodium/chloride transporter], member 3 [SLC12A3]) gene on chromosome $16[3,4]$.

This syndrome may be diagnosed clinically or by renal clearance test; it may also be diagnosed by identifying SLC12A3 gene mutations and renal biopsy. We present a newly diagnosed case of Gitelman syndrome with hypokalemia in a patient who underwent treatment and observation for Liddle syndrome at Inje University Sanggye Paik Hospital for the past 15 years. This case is also compared to 12 cases previously reported in South Korea.

\section{CASE REPORT}

A 55-year-old man visited Inje University Sanggye Paik Hospi- tal for hypokalemia without characteristic symptoms. His medical history revealed that he had undergone outpatient follow-up in the nephrology division for the past 15 years for presumed Liddle syndrome due to hypokalemia and hypertension observed during examination at the department of otorhinolaryngology at Sanggye Paik Hospital. Upon presentation, his blood pressure and electrolyte levels were checked. His blood pressure and potassium level were 165/100 mm Hg and $3.2 \mathrm{mEq} / \mathrm{L}$, respectively. His 24 -hour ambulatory blood pressure was measured in the outpatient clinic. His average blood pressure was high at 130/94 mm Hg. His serum potassium level was $2.6 \mathrm{mEq} / \mathrm{L}$, and the total carbon dioxide concentration was $32 \mathrm{mmol} / \mathrm{L}$. He was diagnosed with Liddle syndrome on the basis of his hypertension, hypokalemia, and metabolic alkalosis. He was monitored and administered beta-blocker with amiloride, and his electrolyte levels remained stable until this year; however, his hypomagnesemia and hypokalemia redeveloped in May 2015, and his previous hypertension had recovered to a normal range. The patient was hospitalized to determine the cause his electrolyte disorder.

His family history was unremarkable. Examination of his vital 
signs revealed a blood pressure of $120 / 80 \mathrm{~mm} \mathrm{Hg}$, pulse of $80 / \mathrm{min}$, breathing rate of $18 / \mathrm{min}$, and body temperature of $36.8^{\circ} \mathrm{C}$, all within normal ranges, with no other unusual symptoms.

Peripheral blood examination revealed a hemoglobin concentration of $14.4 \mathrm{~g} / \mathrm{dL}$, white blood cell count of 5,840 cells $/ \mathrm{mm}^{3}$ (52.8\% neutrophils), and platelet count of 231,000 cells $/ \mathrm{mm}^{3}$. Biochemical examinations revealed a blood urea nitrogen concentration of $17.4 \mathrm{mg} / \mathrm{dL}$; creatinine concentration of $0.92 \mathrm{mg} / \mathrm{dL}$; and serum electrolyte ( $\mathrm{Na}, \mathrm{K}$, and $\mathrm{Cl}$ ) levels of 141, 3.2, and $103 \mathrm{mEq} / \mathrm{L}$, respectively. Arterial blood gas analysis showed a $\mathrm{pH}$ of 7.438; partial pressure of carbon dioxide, $44.9 \mathrm{~mm} \mathrm{Hg}$; partial pressure of oxygen, $74.8 \mathrm{~mm} \mathrm{Hg}$; and $\mathrm{HCO}_{3}$ concentration, $29.7 \mathrm{mEq} / \mathrm{L}$. The serum osmolality was $273 \mathrm{mOsm} / \mathrm{kg}$, while the urinary osmolality was $440 \mathrm{mOsm} / \mathrm{kg}$, serum magnesium $(\mathrm{Mg})$ concentration was $1.9 \mathrm{mg} / \mathrm{dL}$, plasma renin activity was $0.94 \mathrm{ng} / \mathrm{mL} / \mathrm{hr}$ (reference range, 1.31 to $3.95 \mathrm{ng} / \mathrm{mL} / \mathrm{hr}$ ); and aldosterone level was $26 \mathrm{ng} / \mathrm{dL}$ (reference range, 2.7 to $27.2 \mathrm{ng} / \mathrm{dL}$ ). A 24-hour urine examination revealed the $\mathrm{Na}, \mathrm{K}, \mathrm{Cl}, \mathrm{Ca}$, and $\mathrm{Mg}$ concentrations of $61.7 \mathrm{mEq} /$ day, $71.2 \mathrm{mEq} /$ day, $102.5 \mathrm{mEq} /$ day, $7 \mathrm{mg} /$ day, and $62.3 \mathrm{mg} /$ day, respectively. Thyroid hormone levels were within the normal range.

A 24-hour ambulatory blood pressure check revealed maximum, minimum, and mean daytime systolic blood pressures of 136,98 , and 112/83 mm Hg, respectively, and 115, 103, and 110/78 $\mathrm{mm} \mathrm{Hg}$ at nighttime, respectively. His overall average blood pressure was 112/82 $\mathrm{mm} \mathrm{Hg}$, which was considered normal.

A renal clearance test was performed to compare the results of the water loading test, and the clearance and reabsorption of chloride after administration of thiazide and furosemide was performed. Chloride clearance increased by $2.8 \mathrm{~mL} / \mathrm{min}$, from 2.45 $\mathrm{mL} / \mathrm{min}$ to $5.25 \mathrm{~mL} / \mathrm{min}$, after administration of thiazide, compared to $46.22 \mathrm{~mL} / \mathrm{min}$, a difference of $43.77 \mathrm{~mL} / \mathrm{min}$, after administration of furosemide. The chloride reabsorption rate decreased by $18.15 \%$, from $70.61 \%$ to $52.46 \%$, after administration of thiazide, while it was $44.79 \%$ at a difference of $25.82 \%$, after administration of furosemide.

The patient was taking daily oral $\mathrm{KCl}(45 \mathrm{mEq})$ and $\mathrm{MgO}$ (500 $\mathrm{mg}$ ) and received outpatient monitoring, with consistent $\mathrm{K}$ and Mg levels of $3.7 \mathrm{mEq} / \mathrm{L}$ and $1.9 \mathrm{~g} / \mathrm{dL}$, respectively.

\section{DISCUSSION}

This case was of a patient without characteristic symptoms, electrolyte disorders in blood tests, or previous hypertension; however, he had been diagnosed with hypertension when he visited our hospital 15 years prior.

At that time, he was presumed to have Liddle syndrome, received medication delivery, and his electrolyte levels were normalized. He had been monitored for 15 years, until the electrolyte disorder reappeared without hypertension; therefore, new diagnostic tests were performed to determine the cause of his electrolyte disorder. A renal clearance test and renal biopsy were conducted for suspected Gitelman syndrome. This study also assessed the clinical differences and aspects of this case in comparison to cases previously reported in South Korea.

\section{Clinical aspects of patients with Gitelman syndrome in South Korea}

Both the case in our hospital and 12 cases [5-11] reported in South Korea had decreased potassium levels with a mean value of $2.6 \mathrm{mEq} / \mathrm{L}$. Blood pressure was normal or below normal with a mean value of $107 / 68 \mathrm{~mm} \mathrm{Hg}$.

Six cases were those of patients in their teens, while three cases each were those of patients in their 20s and 30s with an average age of 26 years. Eight cases were of male patients and five of female patients.

All but two patients tested positive for metabolic alkalosis, and the mean serum $\mathrm{Mg}$ level was $1.5 \mathrm{mg} / \mathrm{dL}$, a reduced level in all patients. The mean value of plasma renin activity was $17 \mathrm{ng} / \mathrm{dL} / \mathrm{hr}$, which was increased in all patients; however, plasma aldosterone levels were normal in six cases with a mean value of $27.4 \mathrm{ng} / \mathrm{dL}$. In general, while patients with Gitelman syndrome often have increased concentrations of plasma aldosterone, it is not uncommon for it to be within the normal range, which is likely due to the effect of hypokalemia itself directly inhibiting adrenal production of aldosterone [12].

Urinary calcium excretion was reduced in all but two cases with a mean value of $37 \mathrm{mg} / \mathrm{dL}$ (Table 1 ).

\section{Renal clearance test}

Renal clearance tests were performed to assist in the diagnosis of Gitelman syndrome in 11 of 13 cases. In all cases, administration of furosemide resulted in an average chloride clearance increase of $21.2 \mathrm{~mL} / \mathrm{min}$, compared to $4.0 \mathrm{~mL} / \mathrm{min}$, after the administration of thiazide. The distal fractional chloride reabsorption also decreased by $45.4 \%$ following furosemide administration, from $63.8 \%$ to $18.4 \%$, compared to a $1.4 \%$ decrease to $62.4 \%$ fol- 
Park JH, et al. - Laboratory Test and Diagnosis of Gitelman Sydrome

Table 1. Initial presentation and laboratory data

\begin{tabular}{|c|c|c|c|c|c|c|c|c|c|c|c|c|c|c|}
\hline \multirow{2}{*}{ Characteristic } & \multicolumn{13}{|c|}{ Patient in our case } & \multirow{2}{*}{$\begin{array}{l}\text { Mean } \\
\text { value }\end{array}$} \\
\hline & 1 & 2 & 3 & 4 & 5 & 6 & 7 & 8 & 9 & 10 & 11 & 12 & 13 & \\
\hline Age (yr) & 55 & 16 & 19 & 18 & 18 & 24 & 34 & 38 & 19 & 28 & 19 & 21 & 32 & 26 \\
\hline Sex & $M$ & $\mathrm{~F}$ & M & M & M & $\mathrm{F}$ & $\mathrm{F}$ & $\mathrm{F}$ & M & $\mathrm{F}$ & $M$ & M & M & \\
\hline \multicolumn{15}{|l|}{ Serum } \\
\hline Sodium (mEq/L) & 141 & 135 & 136 & 142 & 137 & 135 & 133 & 145 & 142 & 135 & 139 & 140 & 136 & 138 \\
\hline Potassium (mEq/L) & 3.2 & 2.8 & 3.2 & 2.9 & 3 & 1.9 & 2.9 & 2.5 & 2.7 & 2.1 & 2.3 & 2.1 & 2.4 & 2.6 \\
\hline Chloride (mEq/L) & 103 & 93 & 90 & 97 & 100 & 94 & 90 & 96 & 102 & 76 & 95 & 102 & 94 & 94 \\
\hline Calcium (mg/dL) & 8.9 & 10.7 & 10.4 & 9.7 & 9.2 & 9.8 & 10.2 & 10 & 8.5 & 10.2 & 9.8 & 10.1 & 11.1 & 9.8 \\
\hline Phosphorus (mg/dL) & 3.2 & 4.3 & 3.8 & 4.4 & 4.1 & 3.8 & 3.2 & 3.4 & 3.4 & 3.2 & 3.5 & 3.6 & $\mathrm{NR}$ & 3.6 \\
\hline Magnesium (mg/dL) & 1.9 & 1.4 & 1.6 & 1.5 & 1.4 & 1.1 & 1.4 & 1.7 & 1.6 & 1.5 & $\begin{array}{c}0.38 \\
\text { (ionized) }\end{array}$ & 1.13 & 2.1 & 1.5 \\
\hline Plasma renin activity (ng/mL/hr) & 0.94 & 32.8 & 117 & 11 & 43.8 & 14.7 & 10.4 & 15.9 & 19.2 & 33.1 & 5.3 & 4.8 & 19.1 & 17 \\
\hline Plasma aldosterone (ng/dL) & 26 & 40.3 & 90.6 & 80.8 & 10.4 & 14.7 & 19.9 & 14.6 & 22 & 11.7 & 3 & 6.1 & 16.5 & 27.4 \\
\hline \multicolumn{15}{|l|}{ Urine } \\
\hline Sodium (mEq/day) & 61.7 & 210 & 172 & 186 & 180 & 209 & 218 & 256 & NR & NR & NR & NR & NR & 186 \\
\hline Potassium (mEq/day) & 71.2 & 93 & 226 & 57 & 38 & 33 & 78 & 132.3 & 94.8 & 129 & 61.4 & 142 & NR & 96.3 \\
\hline Calcium (mg/day) & 7.1 & 8 & 96 & 63 & 19 & 14 & 17 & 123 & 14 & 18 & 8.3 & 14 & 91.8 & 37 \\
\hline Plasma pH & 7.43 & 7.42 & NR & 7.5 & 7.6 & 7.54 & 7.47 & 7.53 & 7.44 & 7.59 & 7.51 & 7.45 & 7.52 & 7.5 \\
\hline Blood pressure (mm Hg) & $120 / 80$ & $110 / 80$ & $120 / 70$ & $90 / 60$ & $110 / 60$ & $110 / 70$ & $110 / 70$ & $100 / 70$ & $100 / 60$ & $80 / 50$ & NR & $120 / 75$ & $120 / 80$ & $107 / 68$ \\
\hline
\end{tabular}

$M$, male; F, female; NR, not reported.

Table 2. Result of renal clearance test

\begin{tabular}{|c|c|c|c|c|c|c|c|c|c|c|c|c|c|c|}
\hline \multirow{2}{*}{ Renal clearance test } & \multicolumn{13}{|c|}{ Patient in our case } & \multirow{2}{*}{$\begin{array}{l}\text { Mean } \\
\text { value }\end{array}$} \\
\hline & 1 & 2 & 3 & 4 & 5 & 6 & 7 & 8 & 9 & 10 & 11 & 12 & 13 & \\
\hline Minimal urine osmolality & 79 & 71 & 140 & 93 & 77 & NR & 98 & NR & NR & NR & 103 & NR & NR & 94 \\
\hline \multicolumn{15}{|c|}{ Chloride clearance (mL/min) } \\
\hline Basal & 2.4 & 0.8 & 3 & 2.7 & 2 & 2.3 & 2.2 & 4.3 & 4.2 & NR & 3 & NR & NR & 2.6 \\
\hline Furosemide loading & 46.2 & 8.6 & 11.6 & 19.7 & 25.2 & 11.6 & 21.8 & 10.5 & 36.4 & NR & NR & NR & NR & 21.2 \\
\hline Thiazide loading & 5.2 & 1.1 & 8.1 & NR & 2.6 & 1.9 & 5.4 & 5.8 & 2 & NR & NR & NR & NR & 4 \\
\hline \multicolumn{15}{|c|}{ Distal fractional chloride reabsorption (\%) } \\
\hline Basal & 70.6 & 86.1 & 48.2 & 62.6 & 85.2 & 65 & 65.7 & 45 & 51.9 & NR & 57 & 64.5 & NR & 63.8 \\
\hline Furosemide loading & 44.7 & 9.7 & 14.7 & 6.5 & 35.3 & 14 & 21.7 & 16.4 & 15.6 & NR & NR & 7.8 & NR & 18.64 \\
\hline Thiazide loading & 52.4 & 81.4 & 39.4 & NR & 85.3 & 68 & 58.4 & 58.7 & 58.7 & NR & NR & 59.4 & NR & 62.4 \\
\hline$\Delta \mathrm{FE}_{\mathrm{Cl}}(\%)$ & 2.3 & NR & NR & NR & NR & NR & NR & -0.2 & 0 & NR & 0.9 & NR & NR & 0.75 \\
\hline
\end{tabular}

NR, not reported.

lowing thiazide administration.

In unaffected individuals, thiazide induces the disappearance of $\mathrm{NaCl}$ and reabsorption of calcium in the distal tubule and reduces metabolic alkalosis and excretion of urinary calcium. In contrast, furosemide prevents reabsorption of $\mathrm{NaCl}$ in the ascending loop of Henle, but increases urinary excretion of calcium. Therefore, patients with Gitelman syndrome show similar test results to those of thiazide when administered as a diuretic that inhibits NCCT in the distal tubule [5]. Our patient had renal test results similar to those of all but one of the 13 previous cases; thus, Gitelman syndrome could be diagnosed (Table 2).

\section{Immunochemical testing and renal biopsy for DNA testing}

After renal biopsy is performed to obtain samples from patients suspected of having Gitelman syndrome, immunochemical staining can be used to assess NCCT. Renal tissues from eight of 13 cases were immunochemically tested; three cases showed no NCCT expression, two cases showed decreased expression, and there were unclear findings in three cases. A renal biopsy and immunochemical testing of our patient revealed partial expression of NCCT in the distal convoluted tubule.

Kunchaparty et al. [13] analyzed functional defects of NCCT 

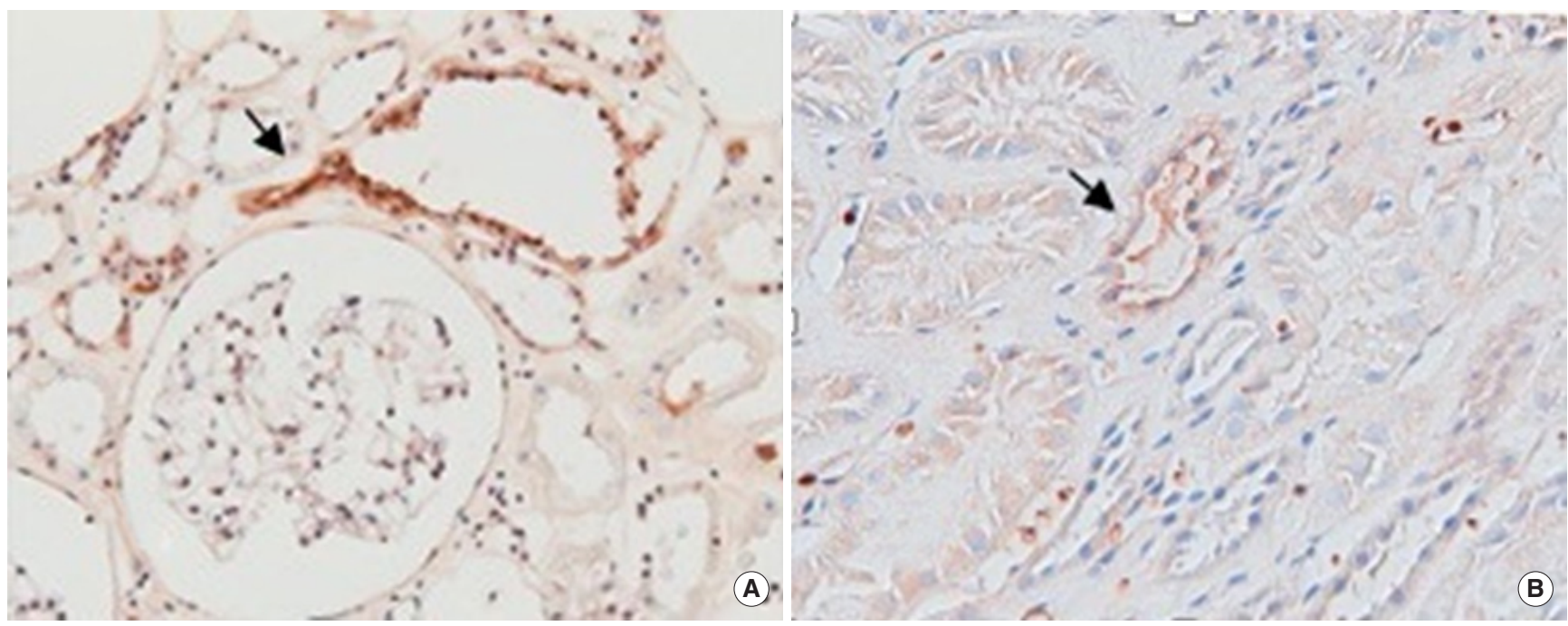

Fig. 1. Immunochemical staining showing partial NCCT expression compared to the control group. Arrow means NCCT expression. (A) Patient in our case. (B) Control (unaffected human). NCCT, Na-Cl cotransporter.

mutations in Gitelman syndrome, reporting that an abnormality in the processing of the NCCT protein leads to Gitelman syndrome, while De Jong et al. [14] proposed two mechanisms for the occurrence of Gitelman syndrome on the basis of mutation types. In type I mutations, NCCT proteins are incompletely saccharified due to interruptions in saccharification preventing them from reaching the cell surface; they are instead trapped in the endoplasmic reticulum or pre-Golgi complex by the mechanism controlling the protein secretory channel.

While saccharification occurs in type II mutations, only some of the processed proteins are trafficked to the cell membrane; however, the NCCT proteins transported to the cell membrane are functional $[13,14]$. Similarly, it is possible for cases to show clinical aspects of Gitelman syndrome; however, normal NCCT expression is seen on immunochemical testing, as the patient in our hospital did (Fig. 1).

Genetic testing allows identification of abnormalities in the $S L$ C12A3 gene on chromosome 16q13; however, its utility for standard diagnosis is limited due to its prohibitive costs, the difficulty in performing the test in ordinary laboratories, and the large number of potential mutations within this gene. This testing was not performed in our patient.

The patient experienced at our hospital had hypertension and hypokalemia in a blood test when he visited the department of nephrology 15 years ago, but he did not want to receive further examination because of his financial situation. He was assumed to have Liddle syndrome, and received examination by taking an electrolyte test regularly and taking amiloride. His electrolyte remained stable for 15 years, but recently, hypokalemia and hypomagnesemia were found again, so for an accurate diagnosis, a new test was conducted.

He was taking beta-blocker as an antihypertensive drug, but his blood pressure remained consistently stable, so three months ago, he discontinued the medication. As a result of a test for measuring 24-hour activity blood pressure conducted after visiting the hospital, it was within a normal range, and putting together with blood test results, renal clearance test and renal biopsy were conducted under the suspicion of Gitelman syndrome.

As a result of a comparison and study with the test results of 12 cases of Gitelman syndrome reported in South Korea, a significant decrease in the NCCT function in the distal tubule was found in a renal clearance test, so Giltelman syndrome could be diagnosed clinically. As a result of a renal biopsy conducted subsequently, a partial expression of NCCT was found, but in type II mutation of Gitelman syndrome, NCCT expression might be observed, so Giltelman syndrome cannot be excluded with this result.

In the future, it would be necessary to conduct more case studies for the establishment of a highly reliable diagnostic method for the diagnosis of Gitelman syndrome, differential diagnosis and the confirmation of prognosis.

\section{REFERENCES}

1. Gitelman HJ, Graham JB, Welt LG. A new familial disorder characterized 
by hypokalemia and hypomagnesemia. Trans Assoc Am Physicians 1966;79:221-35.

2. Tsukamoto T, Kobayashi T, Kawamoto K, Fukase M, Chihara K. Possible discrimination of Gitelman's syndrome from Bartter's syndrome by renal clearance study: report of two cases. Am J Kidney Dis 1995;25:637-41.

3. Simon DB, Nelson-Williams C, Bia MJ, Ellison D, Karet FE, Molina AM, et al. Gitelman's variant of Bartter's syndrome, inherited hypokalaemic alkalosis, is caused by mutations in the thiazide-sensitive $\mathrm{Na-Cl}$ cotransporter. Nat Genet 1996;12:24-30

4. Mastroianni N, De Fusco M, Zollo M, Arrigo G, Zuffardi O, Bettinelli A, et al. Molecular cloning, expression pattern, and chromosomal localization of the human Na-Cl thiazide-sensitive cotransporter (SLC12A3). Genomics 1996;35:486-93.

5. Ki JY, Kim HY, Im JM, Oh KS, Park YS, Kwon SG, et al. Two cases of Gitelman's syndrome diagnosed by renal clearance study. Korean J Nephrol 2001;20:1064-9.

6. Jun HJ, Cho SK, Choi SB, Seo JS, Kang SW, Kim YH, et al. A case of Gitelman's syndrome with chronic hypotension and normomagnesemia. Korean J Nephrol 2007;26:460-4.

7. Moon JD, Han SW, Kim HJ. The effects of magnesium supplementation for correcting hypokalemia in Gitelman syndrome. Korean J Nephrol 2006;25:213-20.
8. Jeon JS, Kim YM, Noh H, Han DC. A case of atypical Gitelman's syndrome with normomagnesemia and normal magnesium excretion. Korean J Nephrol 2004;23:626-9.

9. Shin HS, Park CH. A case of Gitelman's syndrome presented with chest pain and syncope. Korean J Nephrol 2006;25:1013-7.

10. Joo KW, Lee JW, Jang HR, Heo NJ, Jeon US, Oh YK, et al. Reduced urinary excretion of thiazide-sensitive $\mathrm{Na}-\mathrm{Cl}$ cotransporter in Gitelman syndrome: preliminary data. Am J Kidney Dis 2007;50:765-73.

11. Jang HR, Heo NJ, Son MJ, Lee JW, Lee JH, Jeon US, et al. Absence of intact thiazide-sensitive sodium-chloride cotransporter in the renal tissue of a Gitelman's syndrome patient. Korean J Med 2005;69:642-50.

12. Kurtz I. Molecular pathogenesis of Bartter's and Gitelman's syndromes. Kidney Int 1998;54:1396-410.

13. Kunchaparty S, Palcso M, Berkman J, Velazquez H, Desir GV, Bernstein P, et al. Defective processing and expression of thiazide-sensitive $\mathrm{Na}-\mathrm{Cl}$ cotransporter as a cause of Gitelman's syndrome. Am J Physiol 1999;277(4 Pt 2):F643-9.

14. De Jong JC, Van Der Vliet WA, Van Den Heuvel LP, Willems PH, Knoers $\mathrm{NV}$, Bindels RJ. Functional expression of mutations in the human $\mathrm{NaCl}$ cotransporter: evidence for impaired routing mechanisms in Gitelman's syndrome. J Am Soc Nephrol 2002;13:1442-8. 